\title{
Use of a Bacterially Expressed Human Factor IX Light Chain to Develop Polyclonal Antibody Anti-hFIX
}

\author{
Sedigheh Safari • Alireza Zomorodipour • \\ Nour Amirmozaffari • Morteza Daliri Choopari
}

Published online: 12 August 2009

(C) Humana Press 2009

\section{Erratum to: Appl Biochem Biotechnol DOI 10.1007/s12010-008-8506-7}

In reference 28 of the original publication, the journal name is incorrect. It should read "Anal Biochem."

The online version of the original article can be found at http://dx.doi.org/10.1007/s12010-008-8506-7.

S. Safari $\cdot$ A. Zomorodipour $(\bowtie) \cdot$ M. Daliri Choopari National Institute for Genetic Engineering and Biotechnology, P.O. Box 14965/161, Tehran, Iran e-mail: zomorodi@nigeb.ac.ir

S. Safari

Islamic Azad University, Zanjan, Iran

N. Amirmozaffari

Iran University of Medical Science, Tehran, Iran 